Research paper

\title{
Heat transfer investigation in new cooling schemes of a stationary blade trailing edge
}

\author{
A. Beniaiche ${ }^{\text {a, b }}$, A. Ghenaiet ${ }^{\text {c, }}{ }^{*}$, C. Carcasci ${ }^{\text {d }}$, B. Facchini ${ }^{d}$ \\ ${ }^{a}$ Energy Mechanics and Engineering Laboratory(LEMI), Faculty of Engineering, University of M'hamed BOUGARA, Boumerdes, Algeria \\ ${ }^{\mathrm{b}}$ Laboratory of Thermal Power Systems, EcoleMilitairePolytechnique, Bordj El Bahri, Alger 16046, Algeria \\ ${ }^{\mathrm{c}}$ Faculty of Mechanical and Process Engineering, University of Sciences and Technology Houari Boumediene, BP 32 Bab-Ezouar, 16111 Algiers, Algeria \\ d DIEF: Department of Industrial Engineering, University of Florence, Florence, Italy
}

\section{H I G H L I G H T S}

- Investigation of innovative cooling schemes of a wedge shaped discharge trailing edge of a gas turbine blade.

- Measurement of heat transfer coefficient by means of the Thermochromic Liquid Cristal technique.

- Cooling efficiency is influenced by the ribs and tip configuration and the flow regime.

- Nusselt number is correlated against Reynolds number, Prandtl number and fraction of blade height.

\section{A R T I C L E I N F O}

\section{Article history:}

Received 25 September 2014

Accepted 1 May 2015

Available online 9 May 2015

\section{Keywords:}

TLC technique

Stationary gas turbine blade

Trailing edge cooling schemes

Ribs

Pedestals

Heat transfer coefficient

Nusselt number

\begin{abstract}
A B S T R A C T
This paper describes an experimental study for a 30:1 scaled model reproducing an innovative wedge shaped discharge trailing edge (TE) cooling scheme. Three configurations were investigated: Smooth, Ribs $+60^{\circ}$ and Ribs $-60^{\circ}$ with both closed and open tip. Thermochromic Liquid Cristal TLC technique was used to measure the heat transfer coefficient, for a Reynolds number between 10,000 and 40,000 in the stationary condition. The results reveal a direct effect of the Reynolds number and the configurations of cooling scheme on the heat transfer coefficient. Cooling efficiency is influenced by the ribs, the tip configuration and the flow regime. The average Nusselt number at the inlet duct region L0 and the exit trailing edge L1 region is correlated firstly based only on the Reynolds number and secondly on the Reynolds number, Prandtl number and a fraction of blade height. The derived correlations may serve in assessing the effectiveness of blades TE cooling systems.
\end{abstract}

(c) 2015 Elsevier Ltd. All rights reserved.

\section{Introduction}

Modern gas turbines are very powerful and effective owing to increased turbine inlet temperature (TIT), however, advanced air cooling systems allow blades to operate safely below their material strength limit temperature. The casting technologies are manufacturing thin trailing edge (TE) as converging ducts in order to reduce weight and insure a better aerofoil and aerodynamic quality;subsequently this part of the blade is the most critical. The modern design of thin trailing edges arranges for shapes equipped with pedestals in order to increase the internal heat transfer (Han and al. [1]). Unfortunately, this thin trailing region is subject to great aerodynamic, thermal and structural stresses, and this is why the local information on heat transfer is critical in order to prevent,

\footnotetext{
* Corresponding author. Tel./fax: +21321207765 32 .
}

modify and optimize the coolant and to reduce the internal surfaces. Circular pin fin arrays are one of the best technical choices to enhance the overall heat transfer coefficient of the coolant in the trailing edge. On the other side, enlarged pedestals have a lengthened shape of the base section and compared to the circular pin fins, they increase the strength, decrease the pressure losses and increase slightly the heat transfer. Many experimental and numerical studies vis-à-vis the use of pedestals and circular pin fins report the effects of shapes and configurations on the heat transfer. For example, the effects of accelerating the flow, both on the heat transfer and the pressure losses in specific trailing edges considering the pin fins and enlarged pedestals in converging ducts were analysed experimentally by Metzger and Haley [2], Metzger et al. [3,4], Wang and al. [5,6], Hwang and Lui [7,8], and Facchini et al. [9]. Wang et al. [5,6] provided an important experimental survey detailing the heat transfer measurements at the end-wall surface of the pedestals array by using the TLC transient technique. Based on 


\begin{tabular}{|c|c|c|c|}
\hline \multicolumn{2}{|c|}{ Nomenclature } & \multirow[t]{2}{*}{$\mathrm{z} / \mathrm{D}$} & \multirow[t]{2}{*}{$\begin{array}{l}\text { Dimensionless distance with the origin located at the } \\
\text { left plan of the inlet section [-] }\end{array}$} \\
\hline \#丹̊ & Area at a given region & & \\
\hline$D_{h}$ & Hydraulic diameter $[\mathrm{mm}]$ & Greek & \\
\hline $\mathrm{D}$ & $\begin{array}{l}\text { Distance from the pedestal's leading edgeof inlet } \\
\text { section }[32 \mathrm{~mm} \text { ] }\end{array}$ & $\alpha$ & $\begin{array}{l}\text { Wedge angle of the inclined wall }[\mathrm{deg}] \\
\text { Density of coolant }\left[\mathrm{kg}^{-3} \mathrm{~m}^{-3}\right]\end{array}$ \\
\hline$D_{p}$ & Pedestal width $[\mathrm{mm}]$ & $\mu$ & Dynamic viscosity $\left[\mathrm{kg} \cdot \mathrm{m}^{-1} \mathrm{~s}^{-1}\right]$ \\
\hline$d_{t}$ & Pedestal thickness [mm] & & \\
\hline$d_{r}$ & Pedestal's distance in model's radial direction [mm] & \multicolumn{2}{|c|}{ Acronyms } \\
\hline e & Rib height [mm] & LE & Leading Edge \\
\hline$h$ & Heat transfer coefficient $\left[W m^{-2} K^{-1}\right]$ & $L O$ & Inlet duct region \\
\hline$H_{1}$ & Initial duct height $[\mathrm{mm}]$ & $L 1$ & Trailing edge region \\
\hline$k$ & Thermal conductivity $\left[W \mathrm{~m}^{-1} \mathrm{~K}^{-1}\right]$ & $A R$ & Aspect Ratio \\
\hline $\mathrm{dl}$ & Pedestal length [mm] & HTC & Heat transfer coefficient \\
\hline$U_{b}$ & Bulk velocity $\left[\mathrm{ms}^{-1}\right]$ & $i_{\max }$ & line 's local matrix size \\
\hline$\dot{m}$ & Mass flow rate $\left[\mathrm{kg} \mathrm{s}^{-1}\right]$ & $j_{\max }$ & Column's local matrix size \\
\hline$N u, \overline{N u_{\#}}$ & Nusselt number, Average Nusselt number of the \# & TE & Trailing edge \\
\hline & inter pedestal region & TLC & Thermochromic Liquid Crystal PMMA Poly Methyl \\
\hline$p$ & Pressure $[\mathrm{Pa}]$ & & Methacrylate \\
\hline$P_{x}$ & Inter-pedestals distance [mm] & \multirow{2}{*}{\multicolumn{2}{|c|}{ Subscript }} \\
\hline $\operatorname{Pr}$ & Prandtl number [-] & & \\
\hline $\mathrm{P}_{\mathrm{x}} / \mathrm{e}$ & Pitch-to-rib height ratio & co & Coolant \\
\hline$\dot{q}$ & Heat flux density $\left[W^{-2}\right]$ & $f$ & Film \\
\hline Re & Reynolds number & for & Forced convection \\
\hline Ro & Rosbey number & hub & The hub region \\
\hline$s$ & Blade thickness [ $\mathrm{mm}]$ & in & Inlet \\
\hline$T$ & Temperature $\left[{ }^{\circ} \mathrm{C}\right.$ or $\left.\mathrm{K}\right]$ & loss & Conduction losses \\
\hline $\mathrm{T}_{\mathrm{co}}$ & Coolant air temperature at the inlet section $\left[{ }^{\circ} \mathrm{C}\right.$ or $\left.\mathrm{K}\right]$ & $\max$ & Maximum \\
\hline $\mathrm{Xr}$ & Dimensionless radial distance [-] & nat & Natural \\
\hline $\mathrm{x} / \mathrm{Px}$ & Dimensionless distance to the origin located on the & stat & Stationary \\
\hline & mid-span of the L1 region [-] & tip & Tip region \\
\hline$y$ & Rotation axis direction & ro & Referred to ambient conditions \\
\hline $\mathrm{z}$ & Axial direction & $w$ & Wall \\
\hline
\end{tabular}

the same technique, Hwang and Lui [7,8] assessed the heat transfer and the pressure losses of different trailing edge configurations of real blades: wedge, trapezoidal ducts and pin shape. Recently, and thanks to the development of specific equipment (PIV, TLC), a particular attention has been given to the mixed axial-radial flow inside the gas turbine blades by studying the $90^{\circ}$ turned ducts. The data analysis highlighted a significant influence of the orientation of coolant flow and the channel shape on HTC distribution and the pressure drop due to the separated flow structures arising with the flow exiting from the outlet section. Another numerical study carried out by Kulasekharan and Prasad [10] revealed the influences of coolant orientation and channel shape (rectangular and convergent). Later, Liu et al. [11] made detailed heat transfer measurements for inlet Reynolds number $(10,000-40,000)$ in an equilateral triangular channel similar to those in industrial applications with a lateral flow ejection, commonly found in the trailing edge cavities of gas turbine blades. To enhance the heat transfer, tapered ribs were applied to the leading edge and trailing surfaces with a spacing ratio $P_{x} / e=8$ and a ratio of rib height to channel height $e /$ $H=0.125$. Recently, Bianchini et al. [12] produced an experimental survey in an internal cooling system in a 30:1 scaled model using the transparent PMMA to reproduce a typical shape of a high pressure turbine blade trailing edge, where one row of enlarged pedestals is placed at its exit. The measurements of heat transfer coefficient were made by varying Reynolds number from 10,000 to 20,000 in the hub inlet section for both a closed tip and an open tip. The detailed measurements of the heat transfer coefficient were obtained by using a steady state technique with a thin Inconel heating foil and the wide band thermo-chromic liquid crystal technique. Liu et al. [13] accomplished an experimental thermal analysis, in the case of rotor blade channels, on cooling schemes with axial outflow. The thermal field investigations were accomplished inside a rotating channel of trapezoidal cross-section with a flow ejection through slots at the TE. They gave ready-to-use correlations applicable even to models with complex geometries under rotation, but an experimental confirmation is needed to justify the heat transfer performance based on their hypotheses. Bonnaniet al. $[14,15]$ performed an experimental survey of the trailing edge heat transfer based on the 30:1 scaled model for the smooth surface or ribbed surfaces (Ribs $+60^{\circ}$ and Ribs $-60^{\circ}$ orientation) with closed tip and open tip, considering $R e=20000$ and $R o=0-0.3$. For a flat or a ribbed plate, in the stationary cases, the peak values of HTC were revealed near the pedestal leading edge and along the pedestal surface facing the approaching flow, but were shown to decrease with Ro number. As expected, the presence of ribs induced a global increase in HTC values on the wedge section, and the test results showed that the configurations with Ribs $+60^{\circ}$ and an open tip reached the most homogeneous heat transfer distribution all over the heated surface.

In recent times, $\mathrm{Wu}$ et al. [16] conducted an experimental investigation to obtain the heat transfer and pressure drop data for an integral trailing edge cavity section that simulates a novel turbine blade's internal cooling passage with bleed holes. The local heat transfer was measured on both the suction and pressure sides 
by a transient liquid crystal technique, while the pressures at six positions were recorded by pressure transducers, for a high Reynolds number 20000-50,000. The experimental results show that, in the case with bleed flow, the local heat transfer on the pressure side exceeds that on the suction side in the first and second channels. In the case without bleed flow and in the first and third channels, the local heat transfer on the suction side weakens whilst it increases significantly on the pressure side. For the second channel, non-bleed condition leads to a more balanced heat transfer distribution between the upstream and downstream channel. When blocking off the bleed holes, the heat transfer in the first bend region on the suction side declines sharply, while the opposite phenomenon occurs for the second bend region on the pressure side. In both bleed and non-bleed cases, the total pressure of six measurement positions decreases continuously along the channel at the same Reynolds number and it promotes for higher Reynolds numbers. When the bleed holes are blocked, the total pressure at each measurement position appears to increase.

According to this review, the previous studies were focussing on the inlet region of the trailing edge section, but the inter-pedestal regions were not subject to detailed analyses. The present work is an extension of the research work carried out by Bonnani et al. [14,15], based on the same 30:1 scaled model, taking into account, the axial redirection of the inlet radial flow, the surface (Smooth, Ribs $+60^{\circ}$ and Ribs $-60^{\circ}$ ), the tip configuration (open tip or closed tip) and the Reynolds number in between 10000 and 40,000. The test conditions of the present investigation were set to be close to the real behaviour of stationary blades of gas turbines. The obtained 2D maps of HTC distribution are analysed for each type of a cooling scheme and subsequently the correlations of the average Nusselt number at trailing edge are proposed.

\section{Experimental study}

The investigated 30:1 scaled geometry (Fig. 1a and b) corresponds to an innovative cooling scheme reproducing the internal cooling channel of highly loaded gas turbine blades. This geometrical vane was described and analysed by Bianchini et al. [12], Bonnani et al. [14,15] and Beniaiche et al. [17], at the Department of Industrial Engineering, University of Florence. The tested configurations consist in a simple flat plate and two ribbed surfaces (Ribs $+60^{\circ}$ and $\mathrm{Ribs}-60^{\circ}$ with respect to the radial direction (Fig. 1c). Regarding the tip conditions, two cases were considered: a closed tip and an open tip discharging the coolant at an ambient pressure.

\subsection{Investigated geometry}

The channel used to guide the flow from the radial inlet to the tangential outlet is split into two parts: the LO and the L1 region (Fig. 1c). The L0 region consists of a constant height channel and a lateral wall reducing the passage area (to impose a negative gradient) along the radial direction used to redirect the flow towards the trailing edge outlet. The dimensions of the studied geometry are reported in Fig. $1 \mathrm{a}$ and $1 \mathrm{~b}$.

\subsection{Testing}

The present test rig is the same used by Bonnani et al. [14,15]. For more details of the used apparatus and experimental procedure, please refer to references [14,15,and 17]. The steady state TLC technique is used to quantify the HTC values and their distribution over the studied geometries. In fact, the liquid crystals are temperature indicators that modify incident white light and display a colour whose wavelength is proportional to temperature. They can be painted on a surface or suspended in the fluid and used to make visible the distribution of temperature. Normally clear or slightly milky in appearance, liquid crystals change in appearance over a narrow range of temperature called the "colour-play interval" (the temperature interval between first red and last blue reflection), centred around the nominal "event temperature“.

The displayed colour is red at the low temperature margin of the colour-play interval and blue at the high end. Within the colourplay interval, colours change smoothly from red to blue as a function of temperature.

Pure liquid crystal materials are thick, greasy and difficult to deal with, under most heat transfer laboratory conditions. The TLC material is also sensitive to mechanical stress. A microencapsulation process which encloses small portions of liquid crystal material in polymeric material was introduced to solve problems with the stress sensitivity as well as with the chemical deterioration.For more details please refer to [18].

TLC technique was calibrated in the same optical conditions of a real test, and the calibration was checked directly on the test model before each experiment. The experimental procedure is illustrated in Fig. 2, and for more details refer to references [14,15,17].

\subsection{Data reduction}

The blade subject of this study is a component of a high pressure gas turbine which is in contact with gas flows of a temperature up to $1700 \mathrm{~K}$ and a pressures up to $45 \mathrm{bar}$, and presents dimensions in few centimetres. The measurements of heat transfer in effective machine operating conditions, de facto, is impossible, thus it is necessary to obtain less prohibitive conditions by imposing a scaling of the test model based on the theory of similitude. Measurements obtained from scaled models can be reported to the real object through some nondimensional parameters as the Reynolds number, the Mach number, the Prandt number, etc.. Therefore a scaled model can be bigger than the component that reproduces, allowing detailed measurements. The scale is selected taking into account at the same time the nondimensional parameter and requirements for structural strength. The Prandtl number depends only on the considered gas (dry air in our experiments) and not on temperature. This way, the studied heat transfer phenomenon is not influenced by the scaling of the real geometry, and the results will reproduce those of real gas turbine applications. [14,15].

The Reynolds number for the data reduction is calculated at the inlet section (see Fig. 1a) of L0 region as reported by Bianchini et al. [12], Bonnani et al. [14,15] and Beniaiche et al. [17]:

$\operatorname{Re}=\left(\dot{m} D_{h}\right) /\left(\mu A_{h}\right)$

where $\dot{m}$ is the mass flow rate at the inlet section, $\mu$ the dynamic viscosity of the air evaluated at the film temperature at the inlet section of the L0 inlet region, $D_{h}$ the hydraulic diameter and $A_{h}$ the area of the inlet cross section. The heat transfer coefficient is calculated as:

$H T C=\frac{\dot{q}}{T_{w}-T_{c o}}$

where $\dot{q}, \mathrm{~T}_{\mathrm{w}}$ and $\mathrm{T}_{\mathrm{co}}$ are the heat generated by the Inconel heating foil, the wall temperature and the coolant temperature at the inlet section, respectively. This HTC definition must be corrected by including the thermal losses due to conduction through the solid body as follows: 


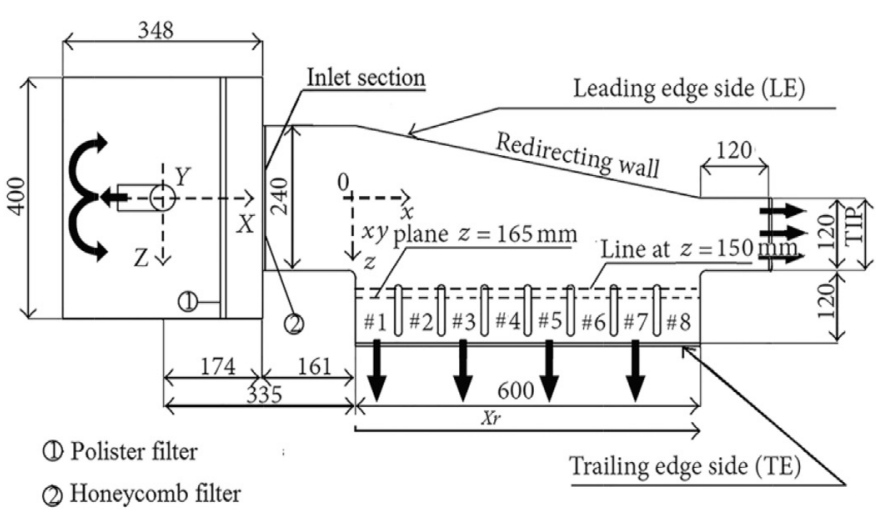

(a)

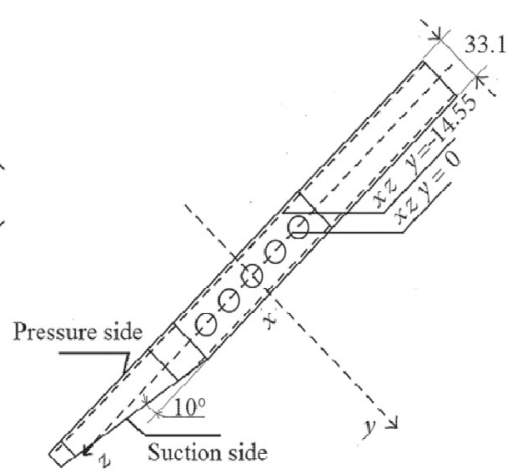

(b)

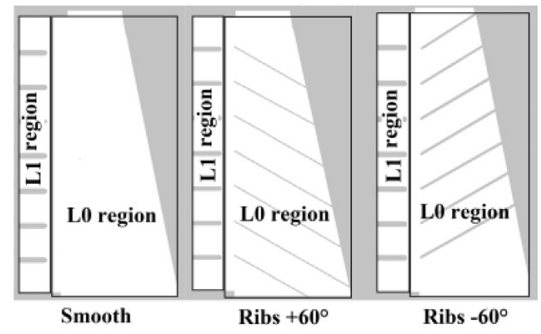

(c)

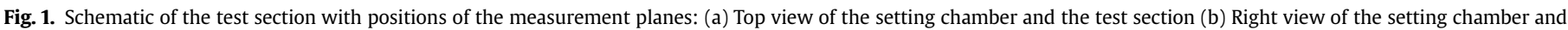
the test section (c) The studied configurations with a highlight of L0 and L1 regions. (dimensions are in $\mathrm{mm}$ ).

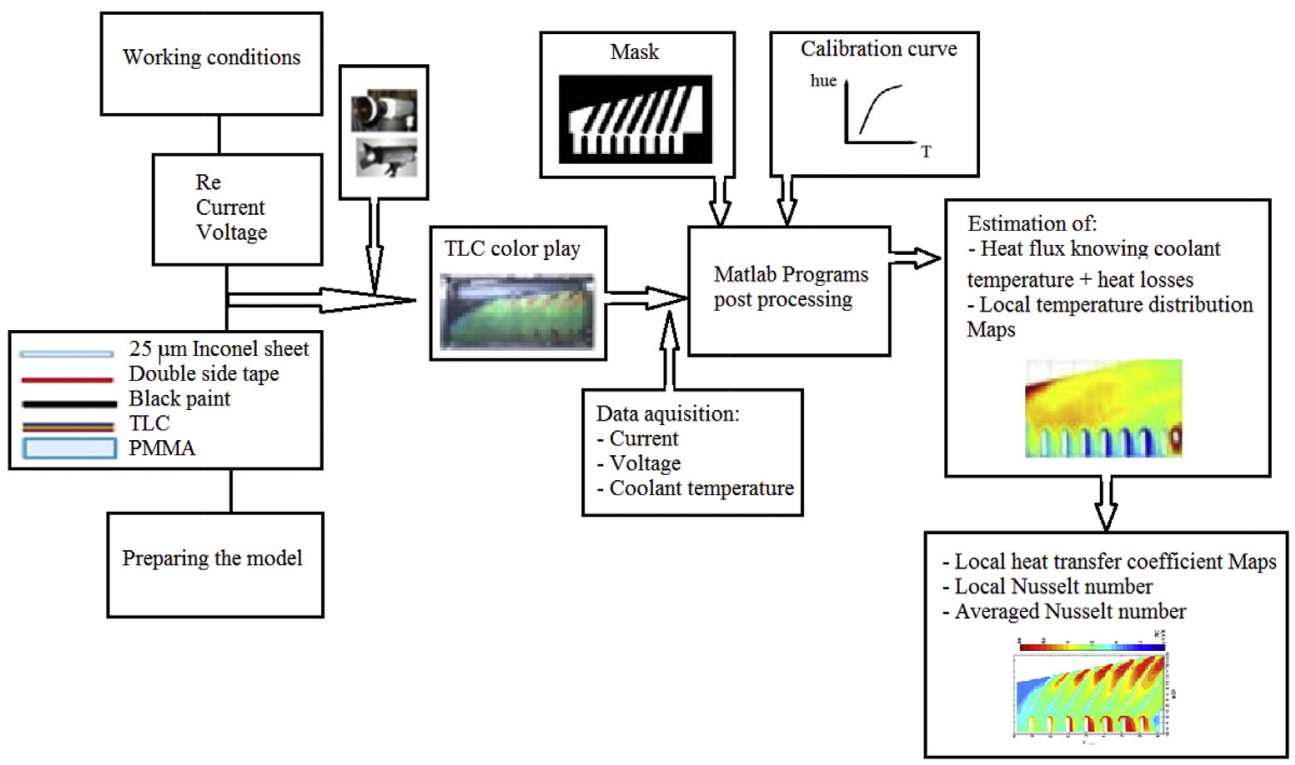

Fig. 2. Experimental data acquisition.

$H=\frac{\dot{q}-\dot{q}_{\text {loss }}}{T_{w}-T_{g}}$

Heat losses are about 3\% in low temperatures and 10\% at high temperatures, which are estimated on the heated side by knowing the thermal conductivity and the thickness of PMMA plate, according to Bonnani et al. [14,15]: $\dot{q}_{\text {loss }}=\frac{\mathrm{k}}{\mathrm{s}} \cdot \frac{\mathrm{T}_{\mathrm{w}}-T_{\text {room }}}{1+\mathrm{k} /\left(\mathrm{s} \cdot \mathrm{h}_{\text {nat }}\right)}$

$\mathrm{T}_{\text {room }}$ is the air temperature before going to the blower. The natural convection heat transfer coefficient of air $h_{\text {nat }}$ is in between 5 and $25 \mathrm{~W} / \mathrm{m}^{2} \mathrm{~K}$ according to heat transfer handbooks [19], and $k$ is the thermal conductivity of the used PMMA: 
The uncertainty analyses were performed according to the standard of ANSI/ASME PTC 19.1[20], based on the Kline and Mc. Clintock method [21]. The accuracy of temperature is $\pm 0.5 \mathrm{~K}$, differential pressure is $\pm 6.9 \mathrm{~Pa}$, mass flow rate is $\pm 2-3 \%$, and heat losses vary from $4 \%$ to $16 \%$ relatively to the maximum heat imposed, and the wall temperature accuracy (the variation of the temperature for repeated tests) is about $\pm 10 \%$.

\section{Results and discussions}

In order to facilitate the analysis of different phenomena related to the cooling, all the plots of HTC have the same colour range and the same scale. The $x / P_{x}$ is a fraction of the radial distance with the origin located on the mid-span of the $\mathrm{L} 1$ region, and $\mathrm{z} / \mathrm{D}$ is a dimensionless distance with the origin located at the left plan of the inlet section. $\mathrm{x}, \mathrm{P}_{\mathrm{x}}, \mathrm{z}$ and $\mathrm{D}$ are respectively, the radial distance, the inter-pedestals distance, the axial distance and the distance from pedestal's leading edge to inlet section $(D=32 \mathrm{~mm})$.

\subsection{Closed tip}

Figs. 3 and 4 exhibit that for high Reynolds numbers the values of HTC are high at LO region, especially near the redirecting wall behind the ribs, but tend to decrease from hub to tip. Same figures show that all the cooling configurations have some peculiar features, where two regions of low HTC are noticed (discontinued black circle in Figs. 3 and 4): The first is located in the inter pedestal vane near the hub (region \#1) and the second is located near the tip along the redirecting wall. For each region, the low HTC is attributed to the recirculation zones. Figs. 3 and 4 show that the size of these recirculations zones decreases with the Reynolds number. In fact, the flow is fully developed after crossing the inlet section of the $\mathrm{L} 0$ region $[16,22,23]$, and owing to the fact that the region \#1 is directly positioned at a turning angle of $90^{\circ}$ of the main flow stream, and the average velocity is low. On the other hand, the size of the recirculation zone at the region \#1 reduces the flow cross section; as a result, the heat transfer coefficient is low [24]. Concerning the $\mathrm{L} 0$ region, the shrinkage of its cross section along the $\mathrm{x}$ direction accelerates the flow, resulting in a rise of the heat transfer in this region. In addition to that, the strong turbulence disturbance induces an increase in HTC and helps to sustain an efficient cooling until the downstream parts of the passage, which is in a good agreement with the results obtained by $\mathrm{Wu}$ et al [16].
The heat transfer distribution differs from the smooth to ribbed surfaces due to ribs effect. In fact, without ribs the flow is fully developed inside the $\mathrm{LO}$ region and as much as the coolant flows inside this region interacts with the heated plate and causes a decrease of the heat transfer along the radial direction of L0 region.The distribution of HTC is not uniform, as seen for the smooth surface, where the region near the hub is better cooled than the tip region. However, the existence of ribs disturbs the developed flow inside the LO region and increases the turbulence, and subsequently the heat transfer exchange, as reported by Han et al. [1]. Small recirculation zones appearing just behind the ribs do not allow the main flow to reach the heated plate which causes the low values of HTC seen behind the ribs (Figs. 3b, c and $4 b, c)$. The ribs orientation as highlighted by Figs. $4 \mathrm{c}$ and $5 \mathrm{c}$. Ribs $+60^{\circ}$ and Ribs $-60^{\circ}$ do not have the same HTC distribution. In fact, when the coolant reaches the ribs near the redirecting wall, for example the case of Ribs $+60^{\circ}$, it first interacts with the ribs and the turbulence disturbance increases. Due to ribs orientation, the flow follows the direction of the redirecting wall, and such orientation of the redirecting wall boosts the turbulence disturbance. In addition to the reduction of flow cross section, there is an augmentation of the heat exchange. As moving forwards to the tip, the efficiency of cooling becomes lower due to the increase in the bulk temperature between the main coolant flow and the heated plate as seen from Fig. 5 illustrating the reduction of the coolant temperature potential (efficiency) as noticed by Wu et al. [16] and Gillespie et al. [27] who defined the cooling effciency as follows :

$e=\frac{\left(T_{b}-T_{w}\right)}{\left(T_{c o}-T_{w}\right)}$

where $\mathrm{T}_{\mathrm{b}}$ the bulk temperature, $T_{w}$ the wall temperature and $T_{c o}$ the temperature of the coolant at the inlet section.

For the case of surface of ribs $-60^{\circ}$, this orientation makes the flow going to the direction of the $\mathrm{L} 1$ region instead of the redirecting wall region. The heat exchange efficiency is mainly influenced by the increase of the coolant flow velocity due to reduced flow cross section of L0 as compared to the surface of ribs $+60^{\circ}$. Moreover, for both surfaces of ribs $-60^{\circ}$ and ribs $+60^{\circ}$, the HTC values at the mid of pedestal regions (regions \#3 to \# 6) are lower compared to the flat plate case. This effect may be explained by the rib orientation towards the axial direction which reduces the angle of attack of the coolant facing the leading edge of pedestals, and the

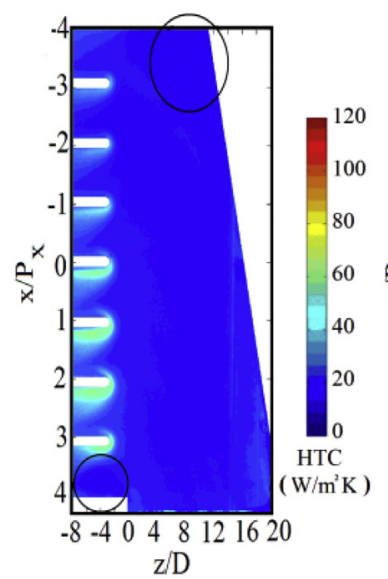

(a)

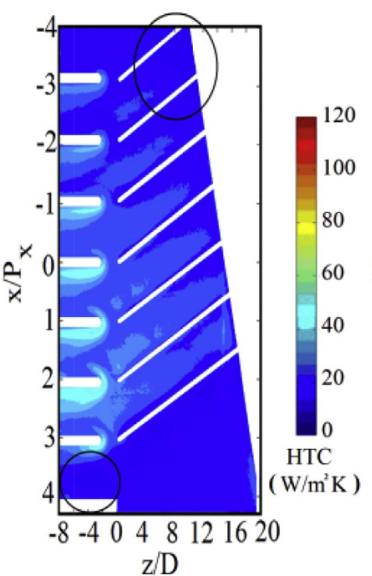

(b)

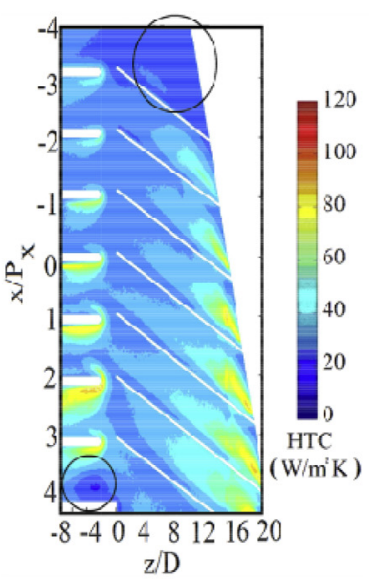

(c)

Fig. 3. $\mathrm{HTC}$ maps $\left[\mathrm{W} / \mathrm{m}^{2} \mathrm{~K}\right]$, Closed tip configuration, $\mathrm{Re}=10000$, (a) Smooth, (b) Ribs $-60^{\circ}$, (c) Ribs $+60^{\circ}$. 


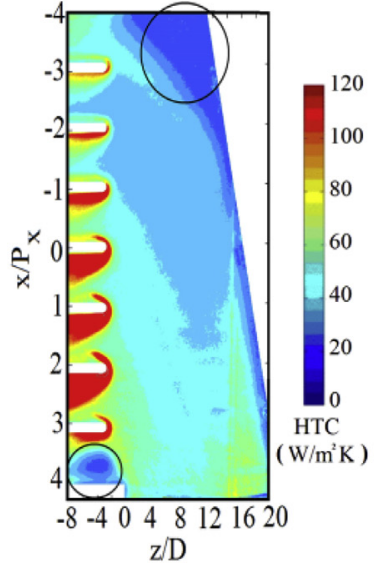

(a)

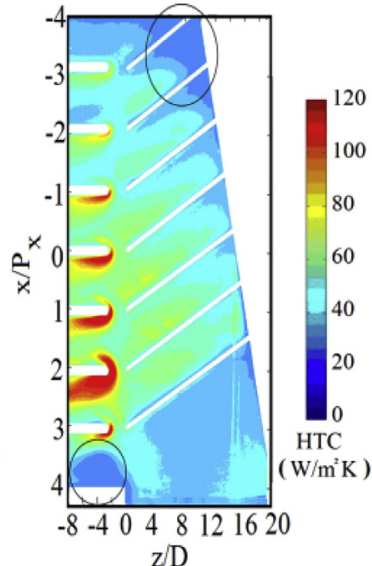

(b)

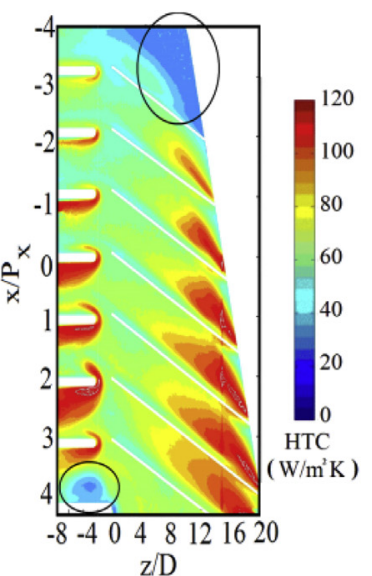

(c)

Fig. 4. HTC maps $\left[\mathrm{W} / \mathrm{m}^{2} \mathrm{~K}\right]$, Closed tip configuration, $R e=40000$, (a) Smooth, (b) Ribs $-60^{\circ}$, (c) Ribs $+60^{\circ}$.

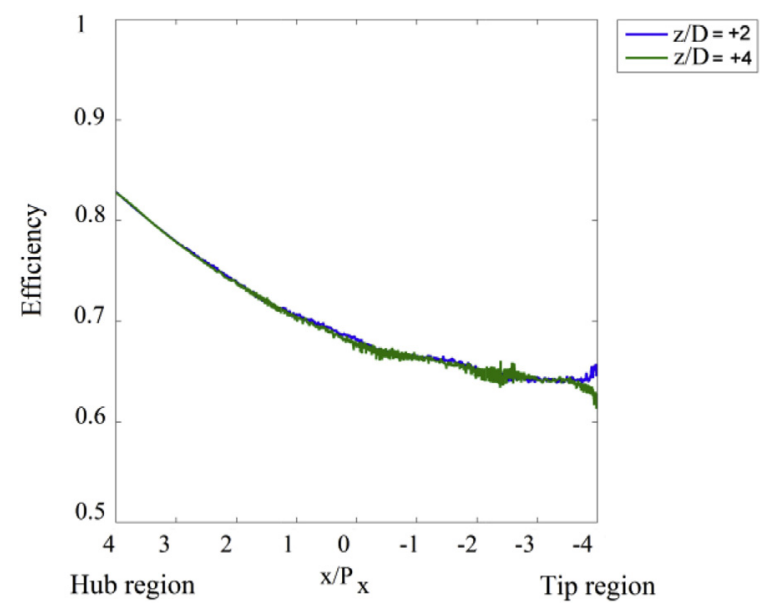

Fig. 5. The coolant temperature potential.

enhancement of the global turbulence inside the LO region and subsequently reducing the heat exchange efficiency.

Concerning the $\mathrm{L} 1$ region, it is possible to notice that the high values of HTC are reached at the leading edge of each pedestal around the stagnation point due to turbulence enhancement, especially for the regions from \#2 to \#7.The coolant reaches the L1 region after being reoriented and accelerated by the redirecting wall. The contraction of the $\mathrm{L} 1$ region in the $\mathrm{z}$ direction decreases the cross section and the flow is accelerated. Figs. 3 and 4 show high values of HTC around the leading edge of each pedestal and its downstream zone (see Fig. 6 for details). In fact, Andrei et al. [22], Andreini et al. [23] and Armellini et al. [25] , have reported that, when the flow reaches the leading edge of the pedestal, the deviation of the approaching boundary layers over the heated plate and the pedestal surface induces the creation of a horse-shoe vortex, which enhances the heat exchange between the main coolant flow and the heated plate and helps more fresh coolant to reach the heated side of the internal geometry. This observation is in good agreement with the one found by $\mathrm{Wu}$ et al. [16].

To support these explanations, Fig. 6 refers to the PIV data of Andrei el al. [22] and Andreini et al. [23], for $R e=20000$ which shows 3D flow structures in the mid of inter-pedestals at the region \#4. As shown, the profiles of the mean velocity component $\mathrm{V}$ (nondimensionalised by the bulk flow velocity in the inlet channel, $U_{b}$ ) in the planes $\mathrm{y}=0, \mathrm{y}=14.55 \mathrm{~mm}, \mathrm{z}=150 \mathrm{~mm}$ and $\mathrm{z}=165 \mathrm{~mm}$. On the suction side of the pedestal, the flow is dominated by the separation zone and no clear imprint of the horseshoe vortex is revealed at the plane $A$ xy 1 . The flow streamlines exhibit a flow
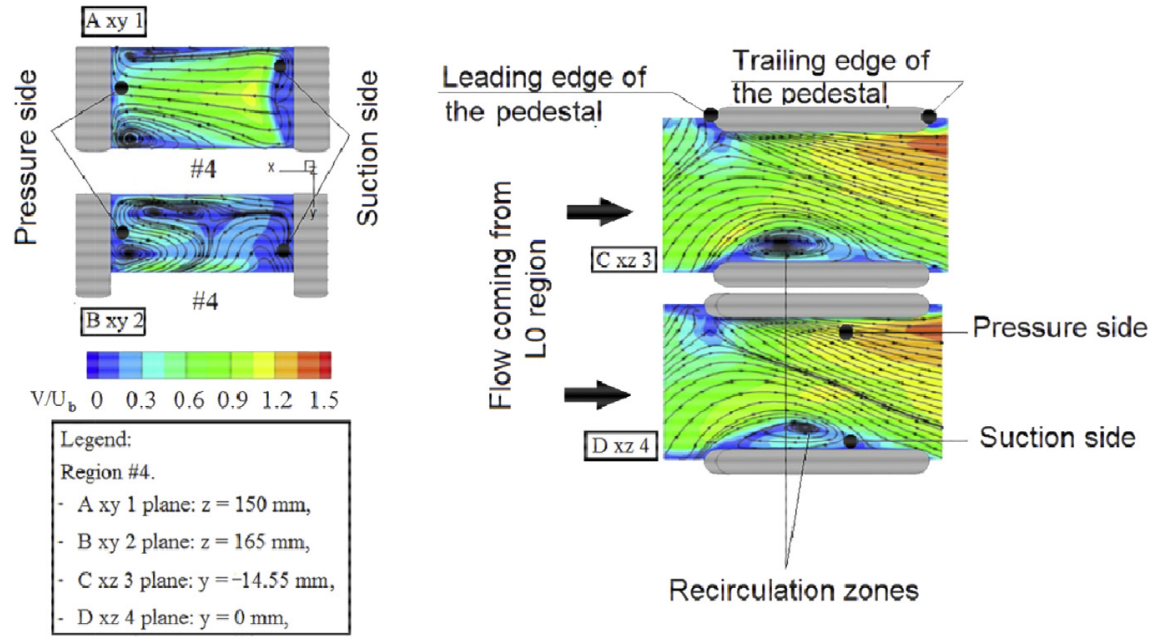

Recirculation zones

Fig. 6. Details of the 3D inter-pedestals flow structures - PIV data $[19,20]$. 


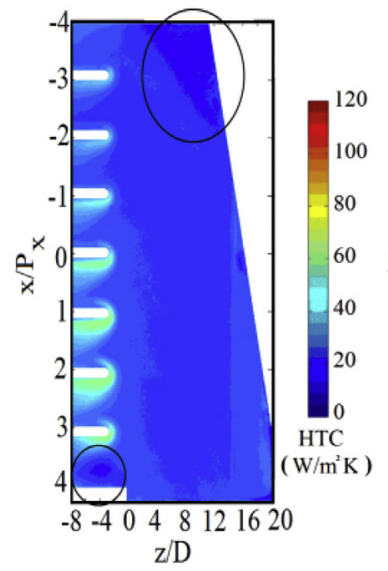

(a)

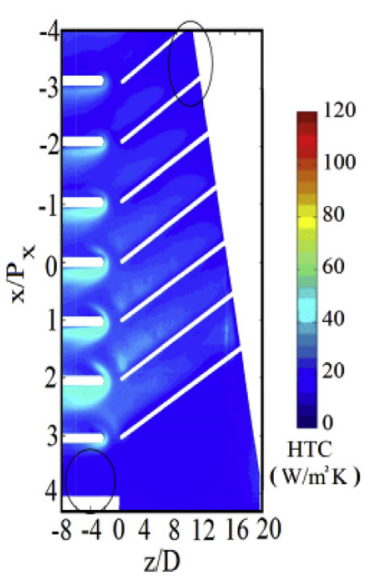

(b)

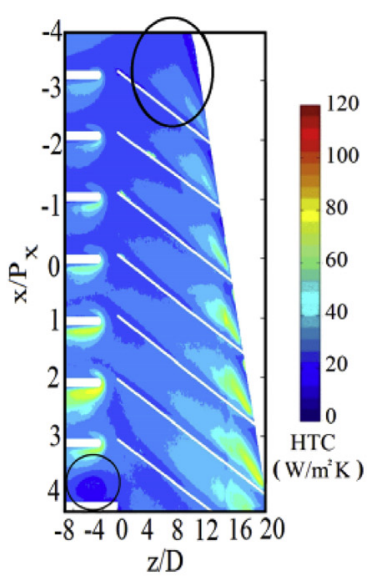

(c)

Fig. 7. HTC maps $\left[\mathrm{W} / \mathrm{m}^{2} \mathrm{~K}\right]$ in region L0, Open tip configuration, Re $=10000$ : (a) Smooth, (b) Ribs $-60^{\circ}$, (c) Ribs $+60^{\circ}$.

motion from the mid-span pedestal towards the end-walls. By moving towards the channel trailing edge, the averaged flow structure is further complicated by the flow acceleration imposed by the narrowing of the channel and the horse-shoe structures appear larger and there is an air replacement between the pressure and the suction sides of the pedestal (Fig. 6: plane B xy2). Similar flow features are observed in other trailing edge inter-pedestal regions, but the only difference, that there is a reduction in the separated flow structures downstream of each pedestal when moving towards the blade tip. The outflow at trailing edge is almost completely axial at the inter-pedestal passage close to the blade hub for which a wide recirculation affects the discharge flow (Fig. 6: planes C xz3 and D xz4). The recirculations zones on the suction side of each pedestal reduce the passage area of the flow and accelerate the flow over the pressure side of the pedestal, and subsequently result in a better cooling of the pressure side. However, the heat exchange between the flow and the heated plate is lower at the suction side of the pedestal due to the recirculation zone. The intensity of the heat exchange is shown to decrease along the $\mathrm{L} 1$ region by going from region \#2 toward region \#8. In fact, as explained before, the cooling efficiency is decreasing as much as the flow moves toward the tip region along the L0 region, because of the interaction with the heated plate and the turbulence disturbances in $\mathrm{L} 0$ region. For that reason, the region $\# 2$ is crossed by a
Table 1

Coefficient $c$ and exponent $n$ in the Nusselt correlation - Closed tip.

\begin{tabular}{|c|c|c|c|c|c|c|}
\hline \multirow{2}{*}{$\begin{array}{l}\text { Inter } \\
\text { pedestals ID }\end{array}$} & \multicolumn{2}{|l|}{ Smooth } & \multicolumn{2}{|c|}{ Ribs $+60^{\circ}$} & \multicolumn{2}{|c|}{ Ribs $-60^{\circ}$} \\
\hline & $\mathrm{C}$ & $\mathrm{n}$ & C & $\mathrm{n}$ & $\mathrm{C}$ & $\mathrm{n}$ \\
\hline LO region & 0.0831 & 0.6500 & 0.0720 & 0.7007 & 0.0771 & 0.6624 \\
\hline \# 8 Tip & 0.3312 & 0.5167 & 0.0617 & 0.6844 & 0.7787 & 0.4292 \\
\hline \# 7 & 0.1013 & 0.646 & 0.1151 & 0.6378 & 0.5269 & 0.4833 \\
\hline$\# 6$ & 0.0653 & 0.7017 & 0.1145 & 0.6386 & 0.3929 & 0.526 \\
\hline \# 5 & 0.1028 & 0.6759 & 0.0944 & 0.6683 & 0.3163 & 0.5639 \\
\hline$\# 4$ & 0.2765 & 0.5906 & 0.1203 & 0.6579 & 0.3498 & 0.5592 \\
\hline$\# 3$ & 0.4672 & 0.5436 & 0.2548 & 0.5886 & 0.1696 & 0.6385 \\
\hline$\# 2$ & 0.5857 & 0.5264 & 0.5598 & 0.5263 & 0.1536 & 0.6556 \\
\hline \# 1 Hub & 2.3992 & 0.3155 & 0.2294 & 0.5775 & 0.4829 & 0.4588 \\
\hline
\end{tabular}

flow having a lower temperature than region \#8 where the flow is warmer. The recirculation zone at the tip region interacts with the coolant as redirected towards the region \#8 by raising its temperature, and as the coolant film temperature is higher the heat exchange decreases at this region.

\subsection{Open tip}

In the open tip configuration, the coolant flow is discharged axially through the exit of trailing edge and a flow rate of $12.5 \%$ is

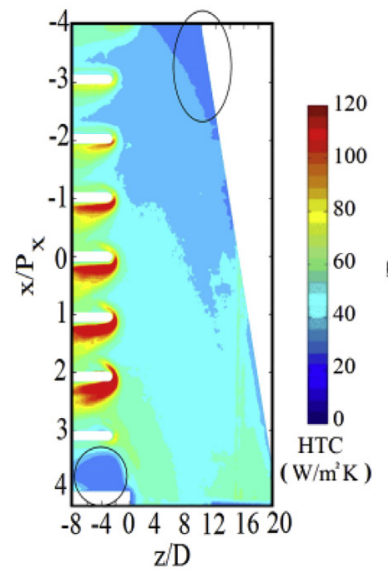

(a)

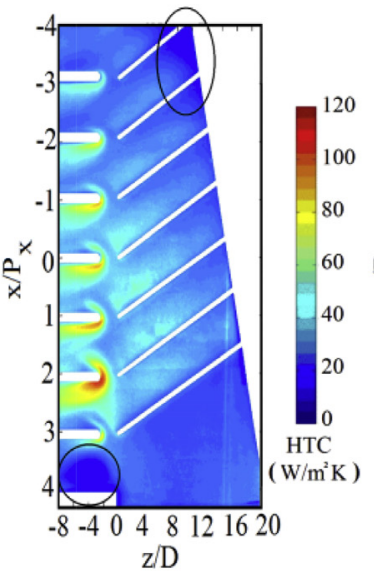

(b)

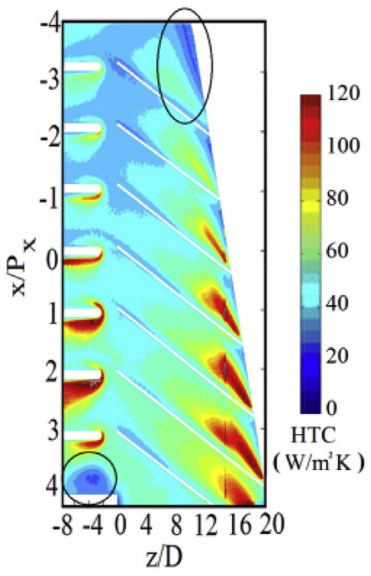

(c)

Fig. 8. HTC maps $\left[\mathrm{W} / \mathrm{m}^{2} \mathrm{~K}\right]$ in region $\mathrm{L} 0$, Open tip configuration, Re $=40000$ : (a) Smooth, (b) Ribs $-60^{\circ}$, (c) Ribs $+60^{\circ}$. 
Table 2

Coefficient $c$ and exponent $n$ in the Nusselt correlation - Open tip.

\begin{tabular}{|c|c|c|c|c|c|c|}
\hline \multirow{2}{*}{$\begin{array}{l}\text { Inter } \\
\text { pedestals ID }\end{array}$} & \multicolumn{2}{|c|}{ Smooth } & \multicolumn{2}{|c|}{ Ribs $+60^{\circ}$} & \multicolumn{2}{|c|}{ Ribs $-60^{\circ}$} \\
\hline & C & $\mathrm{n}$ & C & $\mathrm{n}$ & $C$ & $\mathrm{n}$ \\
\hline LO region & 0.1137 & 0.6238 & 0.0733 & 0.7019 & 0.1526 & 0.5889 \\
\hline \# 8 Tip & 0.7427 & 0.4298 & 0.27965 & 0.52805 & 0.1168 & 0.6092 \\
\hline \# 7 & 0.0683 & 0.6808 & 0.37495 & 0.51709 & 0.1733 & 0.5825 \\
\hline \# 6 & 0.0452 & 0.7272 & 0.07244 & 0.6775 & 0.1763 & 0.5927 \\
\hline \# 5 & 0.0895 & 0.6801 & 0.0449 & 0.7216 & 0.3518 & 0.535 \\
\hline$\# 4$ & 0.0796 & 0.7007 & 0.0708 & 0.6958 & 0.4561 & 0.5145 \\
\hline$\# 3$ & 0.2767 & 0.5834 & 0.1705 & 0.6196 & 0.3372 & 0.5495 \\
\hline$\# 2$ & 0.3548 & 0.5662 & 0.326 & 0.5666 & 0.4700 & 0.5230 \\
\hline \# 1 Hub & 2.1325 & 0.3242 & 0.67187 & 0.46104 & 0.1447 & 0.5805 \\
\hline
\end{tabular}

discharged radially through the five holes at the tip region (Fig. 1b). Figs. 7 and 8 present a sample of obtained HTC, showing that the intensity of HTC values are lower and its distribution is more homogeneous as compared to the closed tip, which may be explained by the disappearance of the recirculation zone at the tip, so that the coolant reaches the upper of blade. This favourable direction is shown to affect the values of HTC at the pedestal's region. The development of the flow inside L0 and L1 regions is practically the same as in the closed tip configuration. The effect of redirecting wall on the cooling flow of the L0 cross section and along the L1 region from hub to tip are the same as explained previously. However, the values of HTC are lower at the L1 region compared to the closed tip, which is attributed to less coolant flow crossing this region and subsequently reducing the flow velocity across interpedestals region and the heat exchange efficiency.

\section{HTC correlations}

Two correlations for estimating the average Nusselt number at L0 and L1 regions have been developed by using the local values of HTC. The post-processing of the TLC images allowed obtaining 2D maps of HTC distribution. For a given $(i, j)$ pixel location of the L1 and LO regions, a $h_{\text {expij }}$ (experimental HTC local value at the $(i, j)$ location) is attributed and a local experimental Nusselt number $N u_{\text {expij }}$ is evaluated as follows:

$N u_{\text {exp } i j}=\frac{h_{\text {expij }} D_{h}}{k_{c o}}$

where $h_{\text {expij }}$ is the experimental HTC local value at the $(i, j)$ location of the regions' matrix, $D_{h}$ the hydraulic diameter, and $k_{c o}$ the coolant thermal conductivity estimated at film temperature $T_{f}$.

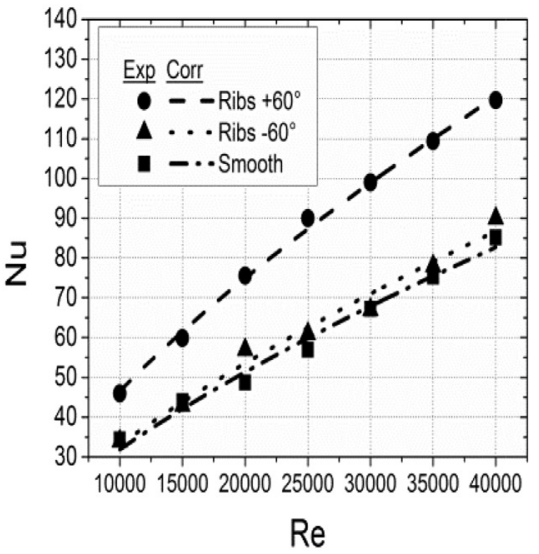

(a)

\subsection{Simple correlations}

A simple correlation form is proposed for different cooling schemes (smooth, $+60^{\circ}$ ribs and $-60^{\circ}$ ribs, with open or closed tip) as follows:

$\overline{N u_{\# \AA}}=c \cdot R e^{n}, \quad$ with $\AA=\{L 0,1,2,3,4,5,6,7,8\}$

The coefficient $c$ and the exponent $n$ are determined by minimizing the standard deviation between the curve fittings and the experimental data. Each data point is the average of six repeated tests with about $10 \%$ of uncertainly for each Reynolds number.

For the L0 region, all the data points were fitted for the range of Reynolds numbers in between 10000 and 40000. The obtained $c$ and $n$ of the simple correlation form (eqn. 7) are listed in Tables 1 and 2. Fig. 9 summerises the obtained results for the L0 region for different cooling configurations. Concerning the L1 region, the derived correlation as presented in Figs. 10 and 11, exhibit a maximum discrepancy within $\pm 10 \%$ for the closed tip; however, for the open tip the discrepancies are within $\pm 13 \%$. As a conclusion, there is a good agreement between the derived correlations and the experimental data.

\subsection{Complex correlations}

In the previous simple correlation form (eqn. 7), for each specific \#A region, the obtained fitting curves well predict the variation of the Nusselt number when the Reynolds number increases. In the open literature, it has been often stated that the heat transfer is not the same along the radial direction $[1,12,14,22,23,25,27]$. However, no such kind of correlations was provided with interest to the effect of radial position of pedestals on the heat transfer exchange (this phenomena is more emphasised by the rotating case), which is a step towards a good design of the internal cooling schemes of the blade TE.

This proposed complex correlation considers the variation of the aero-thermal field along the radial direction of the $\mathrm{L} 1$ region (height). Consequently, the average Nusselt number is a function of $\mathrm{Re}$ and $\mathrm{Pr}$ in addition to the fraction of radial distance $\mathrm{Xr}$; using the following equation:

$$
\begin{aligned}
\overline{N u_{\# \AA}} & \left.=\frac{\sum_{i=1}^{i \max } \sum_{j=1}^{j \max }\left(N u_{\exp i j}\right)}{i \max \cdot j \max }\right]_{\# \AA=L 1 \text { region }} \\
& =c 1 \cdot \operatorname{Re}^{c 2} \cdot \operatorname{Pr}^{c 3} \cdot X r^{c 4}
\end{aligned}
$$

Constants $c 1, c 2, c 3$ and $c 4$ are to be determined.

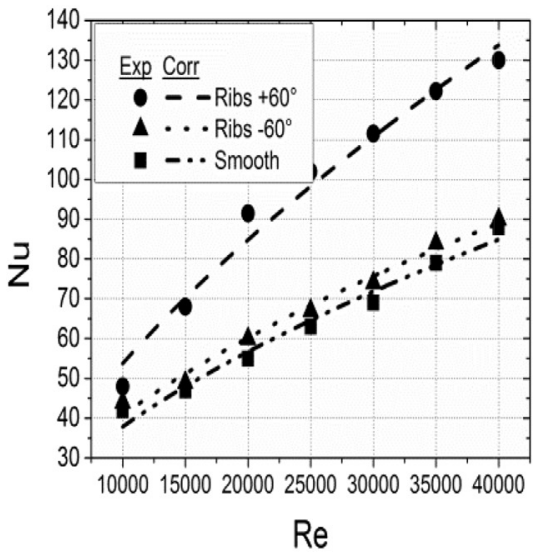

(b)

Fig. 9. Average Nusselt number in L0 region for (a) Closed tip, (b) Open tip. 


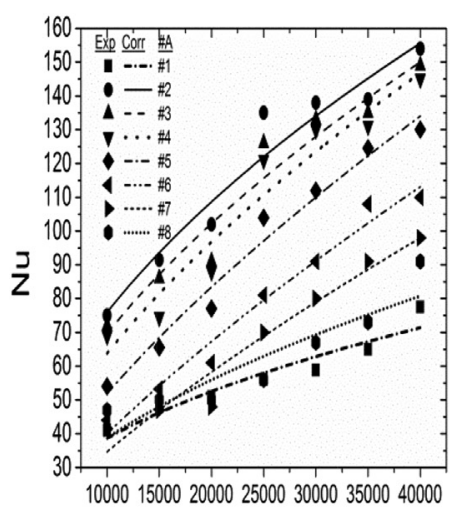

$\operatorname{Re}$

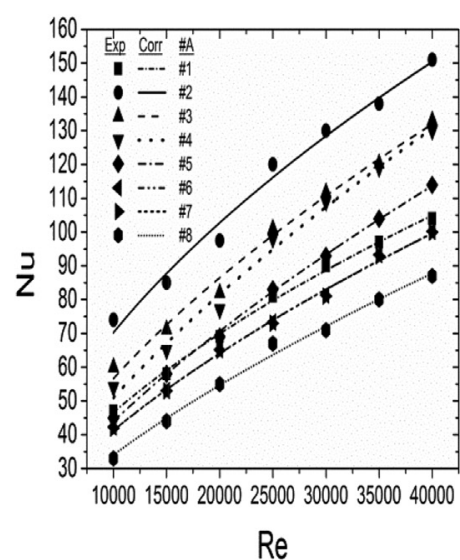

(b)

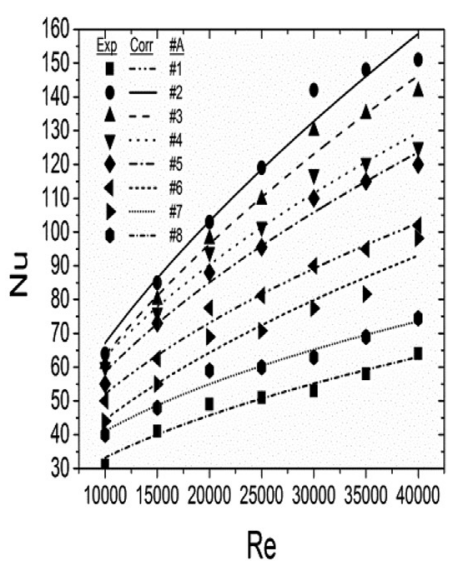

(c)

Fig. 10. Correlated Nusselt number, Closed tip: (a) Smooth, (b) Ribs $+60^{\circ}$ and (c) Ribs $-60^{\circ}$.

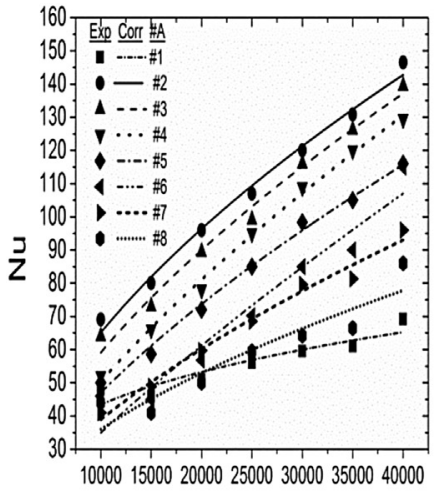

$\operatorname{Re}$

(a)

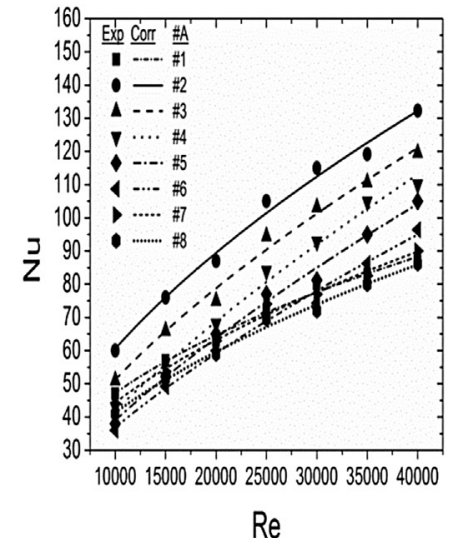

(b)

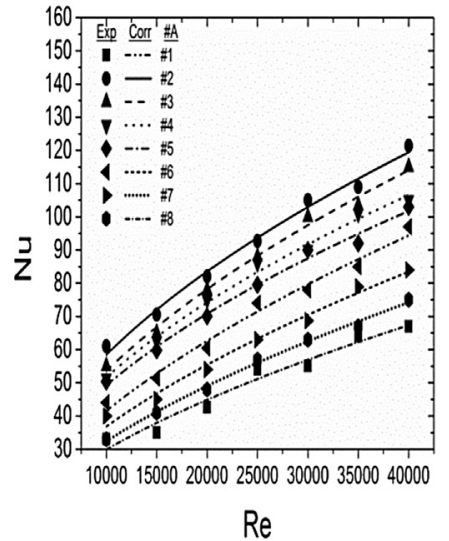

(c)

Fig. 11. Correlated Nusselt number, Open tip: (a) Smooth, (b) Ribs $+60^{\circ}$ and (c) Ribs $-60^{\circ}$.

From the experimental results, the region \#1 reveals a minimum value of HTC, and for this reason, it was decided not including it in the fitting procedure.

After defining the different related parameters in the proposed correlation and constraints, a nonlinear multiple variables fitting procedure was used to determine the unknown coefficients. Table 3 summarizes the obtained coefficients and Fig. 12 illustrates the comparison between the obtained data using the complex correlation and those from experimentation for the surface of Ribs $+60^{\circ}$ and open tip. Generally there is a good egreement between the experimental data and the correlation results with a relative error less than $\pm 16 \%$. A good fitting represents a good agreement between the data and the model, and it is reasonable to say that it represents a good estimation of the unknown parameters. This seems reasonable but unfortunately not always true [26], and one may have a good fitting without having a good regression model.

Table 3

Coefficients of the Nusselt number correlations.

\begin{tabular}{llllll}
\hline & Surface case & c1 & c2 & c3 & c4 \\
\hline \multirow{2}{*}{ Open tip } & Smooth & 0.12800 & 0.62260 & 0.39910 & -0.33970 \\
& Ribs $+60^{\circ}$ & 0.13610 & 0.61690 & 0.39980 & -0.26653 \\
& Ribs $-60^{\circ}$ & 0.27530 & 0.54920 & 0.39970 & -0.28470 \\
Closed tip & Smooth & 0.15128 & 0.61037 & 0.39800 & -0.33033 \\
& Ribs $+60^{\circ}$ & 0.13347 & 0.62786 & 0.39960 & -0.33563 \\
& Ribs $-60^{\circ}$ & 0.39301 & 0.52692 & 0.39500 & -0.32011 \\
\hline
\end{tabular}

So, the difference in accuracy might be attributed to the fact that the simple correlation form is a mono variable exponent function, whereas the second one is a complex nonlinear multi-variables function.

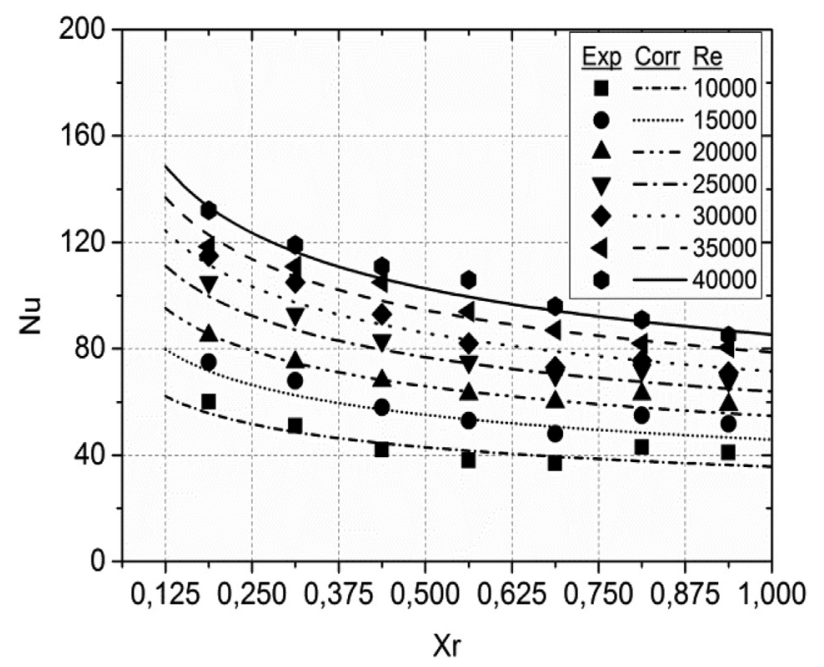

Fig. 12. Comparison between complex correlation form and experimentation data, Open tip, Ribs $+60^{\circ}$. 


\section{Conclusion}

The steady state TLC was used to investigate the internal heat transfer of an innovative cooling scheme for a TE of a stationary blade, considering a smooth, Ribs $+60^{\circ}$ and Ribs $-60^{\circ}$, for closed and open tip. The obtained maps of HTC for Re between 10000-40000 revealed recirculation zones of low HTC near the hub, and another (only for the closed tip) at the tip. The heat transfer is shown to be influenced by $R e$ (decrease with the increased $\mathrm{Re}$ ) and the surface and the tip configuration. The results of the proposed simple and complex correlations agree well with the experimentation data, within maximum discrepancies of $\pm 10 \%$ to $\pm 12 \%$ for the simple form and $\pm 16 \%$ for the complex form. These derived correlations may serve in designing new cooling schemes for the TE of NGVs.

\section{Funding}

This research has been supported by the Italian Ministry of Education University and Research

\section{Conflict of interest}

None declared.

\section{Acknowledgements}

Our Acknowledgements go to Dr L.Bonnani, Dr L.Andrei, Dr A. Andereini, Dr M.Pievaroli and all the staff of the Department of the Industrial Engineering University of Florence Italyfor their help and assistance in completing this work.

\section{References}

[1] J.C. Han, S. Dutta, S.V. Ekkad, Gas turbine Heat Transfer and Cooling Technologies, Taylor \& Francis, New York, NY 10001, 2000. ISBN 1-56032-841-X.

[2] E. Metzger, S.W. Haley., Heat Transfer Experiments and Flow Visualization for Arrays of Short Pin Fins, 1982. ASME Paper 82-GT-138.

[3] E. Metzger, R.A. Berry, J.P. Bronson, Developing heat transfer in rectangular ducts with staggered arrays of short pin fins, ASME J. Heat Transf. 104 (1) (1982) 700-706.

[4] E. Metzger, W.B. Shepard, S.W. Haley, Row Resolved Heat Transfer Variations in Pin-fin Arrays Including Effects of Non-uniform Arrays and Flow Convergence, 1986. ASME Paper, 86-GT-132.

[5] Z. Wang, P.T. Ireland, T.V. Jones, Detailed Heat Transfer Coefficient Measurements and Thermal Analysis at Engine Conditions of a Pedestal with Fillet Radii, 1993. ASME Paper GT1993-329.

[6] Z. Wang, T.V. Jones, P.T. Ireland, S.T. Kohler, Measurements of Local Heat Transfer Coefficient over the Full Surface of a Bank of Pedestals with Fillet Radii, 1994. ASME Paper GT1994-307.
[7] J.J. Hwang, C.C. Lui, Measurements of endwall heat transfer and pressure drop in a pin-fin wedge duct, Int. J. Heat Mass Transf. 45 (2002) 877-889.

[8] J.J. Hwang, C.C. Lui, Detailed heat transfer characteristic comparison in straight and 90-deg turned trapezoidal ducts with pin-fin arrays, Int. J. Heat Mass Transf. 42 (1999) 4005-4016.

[9] B. Facchini, C. Carcasci, L. Innocenti, Heat Transfer and Pressure Drop Evaluation in Thin Wedge-shaped Trailing Edge, 2003. ASME Paper GT2003-38197.

[10] N. Kulasekharan, B.V.S. Prasad, Effect of Coolant Entry Orientation on Flow and Heat Transfer in Trailing Region Channels of a Gas Turbine Vane, 2008. ASME Paper GT2008-50343.

[11] Y.H. Liu, M. Huh, L.M. Wright, J.C. Han, Heat Transfer in Trailing Edge, Wedge Shaped Cooling Channels with Slot Ejection under High Rotation Numbers, 2008. ASME Paper, GT2008-50343.

[12] C. Bianchini, L. Bonanni, C. Carcasci, B. Facchini, L. Tarchi, Experimental survey on heat transfer in an internal channel of a trailing edge cooling system, in: $65^{\circ}$ AssociazioneTermotecnicaltaliana National Congress, 2012. ATI12-085.

[13] Y.H. Liu, M. Huh, J.C. Han, High rotation number effect on heat transfer in a trailing edge channel with tapered ribs, Int. J. Heat Fluid Flow 33 (2012) $182-192$.

[14] L. Bonnani, C. Carcasci, B. Facchini, L. Tarchi, Heat transfer measurements and effects of rotation in a trailing edge cooling system, in: $66^{\circ}$ Congresso Nazionale ATI - Rende (Cosenza), 2011.

[15] L. Bonnani, C. Carcasci, C. Facchini, L. Tarchi, Experimental survey on heat transfer in a trailing edge cooling System: effects of rotation in internal cooling ducts, 2012. ASME Paper GT2012-69638.

[16] H. Wu, Y. Liu, G. Xu, Measurements of heat transfer and pressure in a trailing edge cavity of a turbine blade, Chin. J. Aeronaut. 26 (2) (2013) 294-308.

[17] A. Beniaiche, A. Bonanni, C. Carcaci, TLC Measurements of Heat Transfer under Rotating Conditions at High Reynolds Number in an Innovative Trailing Edge Cooling System, 2012. ASME Paper GTIndia2012-9560.

[18] R. Yu, Y. Xu, Uncertainty analyses and its application to Turbulent heat transfer measurements, J. Adv. Condens. Matter Phys. 2012 (2012) 8. Article ID 898104.

[19] M.J. Moran, H.N. Shapiro, B.R. Munson, D.P. DeWitt, Introduction to Thermal Systems Engineering: Thermodynamics, Fluid Mechanics, and Heat Transfer, edition 1, Wiley, John \& Sons, Incorporated, September 2002, p. 345, 0471204900

[20] ASME, Measurement Uncertainty: Instrument and Apparatus, 1985. Vol. ANSI/ ASME PTC 19.1-1985 of Performance Test Code.

[21] S.J. Kline, F.A. McClintock., Describing uncertainties in single sample experiments, Mech. Eng. 75 (1953) 3-8.

[22] L. Andrei, A. Andreini, L. Bonanni, B. Facchini, Heat transfer in internal channel of a blade: effects of rotation in a trailing edge cooling system, in: 10th International Symposium on Experimental Computational Aerothermodynamics of Internal Flows, (ISAIF10-99), 2010.

[23] A. Andreini, C. Bianchini, A. Armellini, L. Casarsa, Flow field analysis of a trailing edge internal cooling channel, GT2011-45724, in: Proceedings of ASME Turbo Expo 2011: Power for Land, Sea and Air, 2011.

[24] M. Pascotto, A. Armellini, Effects of rotation at different channel orientations on the flow field inside a trailing edge internal cooling channel, Hindawi Publ. Corp. Int. J. Rotating Mach. (2013) 19. Article ID 765142.

[25] A. Armellini, L. Casarsa, C. Mucignat, Flow field analysis inside a gas turbine trailing edge cooling channel under static and rotating conditions, Int. J. Heat Fluid Flow 32 (6) (2011) 1147-1159.

[26] FOXES TEAM, Tutorial on Numerical Analysis with Optimization,Nonlinear Fitting and Equations Solving, 2nd Edition, vol. 1, 2006, pp. 71-72.

[27] David R.H. Gillespie, Peter T. Ireland, Geoff M. Dailey, Detailed flow and heat transfer coefficient measurements in a model of an internal cooling geometry employing orthogonal intersecting channels, in: Proc. ASME. 78569, Heat transfer; electric power; industrial and cogeneration, V003T01A104, vol. 3, May 08 2000, http://dx.doi.org/10.1115/2000-GT-0653, 2000-GT-0653. 